\title{
Untargeted Metabolic Profiling of Extracellular Vesicles of SARS-CoV-2-Infected Patients Shows Presence of Potent Anti-Inflammatory Metabolites
}

\author{
Faisal A. Alzahrani 1,2*(D), Mohammed Razeeth Shait Mohammed ${ }^{2} \mathbb{D}$, Saleh Alkarim ${ }^{1}$, Esam I. Azhar ${ }^{3} \mathbb{D}_{\text {, }}$

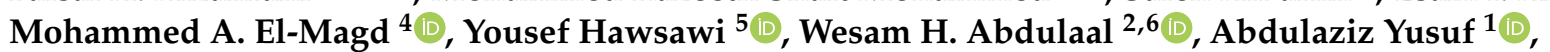 \\ Abdulaziz Alhatmi ${ }^{1}$, Raed Albiheyri ${ }^{7}$ (D), Burhan Fakhurji ${ }^{7,8}$, Bassem Kurdi ${ }^{9}{ }^{\mathbb{D}}$, Tariq A. Madani ${ }^{10}$, \\ Hassan Alguridi ${ }^{1,11}$, Roaa S. Alosaimi ${ }^{12}$ and Mohammad Imran Khan 1,2, ID $^{-}$
}

Citation: Alzahrani, F.A.; Shait Mohammed, M.R.; Alkarim, S.; Azhar E.I.; El-Magd, M.A.; Hawsawi, Y.; Abdulaal, W.H.; Yusuf, A.; Alhatmi, A.; Albiheyri, R.; et al. Untargeted Metabolic Profiling of Extracellular Vesicles of SARS-CoV-2-Infected Patients Shows Presence of Potent Anti-Inflammatory Metabolites. Int. J. Mol. Sci. 2021, 22, 10467. https:// doi.org/10.3390/ijms221910467

Academic Editor: João R. Mesquita

Received: 26 August 2021

Accepted: 25 September 2021

Published: 28 September 2021

Publisher's Note: MDPI stays neutral with regard to jurisdictional claims in published maps and institutional affiliations.

Copyright: (c) 2021 by the authors Licensee MDPI, Basel, Switzerland. This article is an open access article distributed under the terms and conditions of the Creative Commons Attribution (CC BY) license (https:/ / creativecommons.org/licenses/by/ $4.0 /)$.
1 King Fahd Medical Research Center, Embryonic Stem Cells Unit, Department of Biochemistry, Faculty of Science, King Abdulaziz University, Jeddah 21589, Saudi Arabia; skarim@kau.edu.sa (S.A.); a.zi@windowslive.com (A.Y.); mr.abdulaziz1415@hotmail.com (A.A.); dr.alguridi@gmail.com (H.A.)

2 Centre of Artificial Intelligence in Precision Medicines (CAIPM), King Abdulaziz University, Jeddah 21589, Saudi Arabia; razeeth.new@gmail.com (M.R.S.M.); whabdulaal@kau.edu.sa (W.H.A.)

3 King Fahd Medical Research Center, Special Infectious Agents Unit, Medical Laboratory Technology Department, Faculty of Applied Medical Sciences, King Abdulaziz University, Jeddah 21589, Saudi Arabia; eazhar@kau.edu.sa

4 Department of Anatomy \& Embryology, Faculty of Veterinary Medicine, Kafrelsheikh University, Kafrelsheikh 33516, Egypt; mohamed.abouelmagd@vet.kfs.edu.eg

5 Research Center, King Faisal Specialist Hospital and Research Center, P.O. Box 40047, Jeddah 21499, Saudi Arabia; hyousef@kfshrc.edu.sa

6 King Fahd Medical Research Center, Cancer and Mutagenesis Unit, Department of Biochemistry, Faculty of Science, King Abdulaziz University, Jeddah 21589, Saudi Arabia

7 Department of Biological Sciences, Faculty of Science, King Abdulaziz University, Jeddah 21589, Saudi Arabia; ralbiheyri@kau.edu.sa (R.A.); dr.burhan@igene-sa.com (B.F.)

8 iGENE Center, Jeddah 23484, Saudi Arabia

9 Department of Pediatrics, Faculty of Medicine, King Abdulaziz University, Jeddah 21589, Saudi Arabia; bskurdi@kau.edu.sa

10 Department of Medicine, Faculty of Medicine, King Abdulaziz University, P.O. Box 80215, Jeddah 21589, Saudi Arabia; tmadani@kau.edu.sa

11 Jeddah Regional Laboratory, Molecular Biology Department, Ministry of Health, Jeddah 22421, Saudi Arabia

12 East Jeddah General Hospital, Ministry of Health, Jeddah 22253, Saudi Arabia; roalosaimi@moh.gov.sa

* Correspondence: faahalzahrani@kau.edu.sa (F.A.A.); mikhan@kau.edu.sa (M.I.K.)

Abstract: Extracellular vesicles (EVs) carry important biomolecules, including metabolites, and contribute to the spread and pathogenesis of some viruses. However, to date, limited data are available on EV metabolite content that might play a crucial role during infection with the SARSCoV-2 virus. Therefore, this study aimed to perform untargeted metabolomics to identify key metabolites and associated pathways that are present in EVs, isolated from the serum of COVID-19 patients. The results showed the presence of antivirals and antibiotics such as Foscarnet, Indinavir, and lymecycline in EVs from patients treated with these drugs. Moreover, increased levels of anti-inflammatory metabolites such as LysoPS, 7- $\alpha$,25-Dihydroxycholesterol, and 15-d-PGJ2 were detected in EVs from COVID-19 patients when compared with controls. Further, we found decreased levels of metabolites associated with coagulation, such as thromboxane and elaidic acid, in EVs from COVID-19 patients. These findings suggest that EVs not only carry active drug molecules but also anti-inflammatory metabolites, clearly suggesting that exosomes might play a crucial role in negotiating with heightened inflammation during COVID-19 infection. These preliminary results could also pave the way for the identification of novel metabolites that might act as critical regulators of inflammatory pathways during viral infections.

Keywords: extracellular vesicles; metabolomics; COVID-19; 7- $\alpha$,25-Dihydroxycholesterol; 15-d-PGJ2 


\section{Introduction}

Severe acute respiratory syndrome coronavirus 2 (SARS-CoV-2) is a recently detected coronavirus, which resulted in the pandemic spread of Corona Virus Disease 2019 (COVID19). Although its genome sequence is somewhat close to SARS-CoV, the novel virus has improved infectivity and hidden initial clinical signs, hindering early detection of suspected cases and control of SARS-CoV-2 transmission [1,2]. Some researchers attributed these enhanced features to the high-affinity binding of SARS-CoV-2 spike protein (S) to its receptor, angiotensin-converting enzyme 2 (ACE2), attributed to the presence of several mutations in the receptor-binding domain (RBD) of $\mathrm{S}$, especially the novel furin cleavage insert, which is unique to this virus [3-10]. However, these mutations alone may not explain the higher contagious spread of SARS-CoV-2, and there may be other mechanisms that enhance infectivity and escape from host immune responses.

Extracellular vesicles (EVs) are a heterogeneous population of membranous structures released by cells into outer space under both normal and pathophysiologic conditions [11]. The majority of EVs range in diameter from 30 to 100 nanometers and include exosomes from the endosomal compartment and ectosomes from the plasma membrane. EVs are known to be secreted by most of the systemic cell types [12] and can be abundantly found in human serum [13]. EVs contain a wide range of biological molecules, such as DNA, RNA, miRNA, proteins, functional enzymes, cholesterol and sphingomyelin, and metabolites [14]. The lipid bilayer of EVs enables stability of internal cargo molecules while EVs circulate through body fluids. As a result, EVs can transfer their specific cargo to various target cells as a means of regulating target cell physiological and pathological processes, including host immune responses. The specificity of cargo molecules highly depends on the cell type of origin and circumstances of EV release, such as stress, infections, and drug exposures $[15,16]$. However, mechanisms for packaging of specific cargo into EVs remain elusive.

EVs are under intense investigation, as they play a significant role in disease and simultaneously possess the potential for diagnostics as biomarkers of pathological conditions such as cardiovascular disease, Alzheimer's disease, cancer, and viral infection $[13,14,17,18]$. Biogenesis of exosomes shares some cellular components (such as endosomes, multivesicular bodies, and lysosomes) that are hijacked by viruses after entrance into the cell [17]. Concerning their role in viral disease pathogenesis, EVs such as exosomes can transmit nucleic acids and proteins between viral infected and uninfected cells, thereby facilitating cell-to-cell viral transmission and regulating host immune responses. Several viruses such as HBV, HCV, and RSV utilize EVs to infect host cells [13,14,17-19]. Exosomes derived from a cell culture system and patients' sera with complete replication of the HCV genome showed an ability to transmit infection to normal human hepatocytes [18,20]. Moreover, exosomes can activate immune response through induction of cytokine release during cytokine storm associated with respiratory syncytial virus (RSV) infection [17]. Interestingly, the exosomes isolated from the blood of hepatitis B patients contained protein and nucleic acids of HBV, and exosomal contents were also detected in the natural killer cells (NK) and contributed to the suppression of immunity [21]. On the other hand, SARS-CoV was reported to use EVs during infection of AT2 cells [22]. SARS-CoV-2 products were detected in EVs of renal cells of COVID-19 patients [23,24], although other studies did not find SARS-CoV-2 RNA in EVs [25-27]. Exosomes can transmit ACE2 between host cells [28], making recipient cells potentially more prone to virus infection [29]. Viral particles within EVs were reliably detected in samples originated from the patients infected with SARS-CoV-2 [30-33].

Metabolomics provide a unique opportunity for identifying novel biomarkers and biochemical pathways to enhance early detection of disease, providing pathological insights beyond traditional "omics" methods. Quantitative measurement of circulating smallmolecule metabolites that may participate in disease pathogenesis [34] may improve diagnosis, unravel appropriate therapeutic targets, and enable a more precise prognosis of disease outcome [35]. Metabolomics studies have successfully identified biomarkers 
for diagnosis, progression, and treatment response for age-related diseases such as cancer, diabetes, and autoimmune diseases [36-39]. A recent study has reported the presence of an abundant amount of coagulation-related protein Kininogen-1 in EVs, such as exosomes isolated from COVID-19 patients, and suggested that exosomes may act as a reserve of Kininogen-1 [40]. As for EVs and metabolites, GM3-enriched exosomes are associated with COVID-19 severity and progression [41]. Exosomal C-reactive protein (CRP) was detected in the plasma of COVID-19 patients and was positively related to disease severity, suggesting a crucial role for exosomes in CRP transport among host cells [40]. Exosomes from plasma of severe cases (ICU) of COVID-19 had an increased level of the fibrosis markers tenascin-C (TNC) and fibrinogen- $\beta$ (FGB) [25]. Additionally, exosome-based tactics were also recommended to handle COVID-19 [29] or inhibit SARS-CoV-2 infection [42] or as carriers to provide protease inhibitors to combat COVID-19 [43].

Knowing the role of the EVs such as exosomes in SARS-CoV-2 infection could solve some mysterious gaps related to COVID-19 pathogenesis and open new opportunities for the development of effective treatments. The aforementioned data indicate that EVs could play a crucial role in the transmission and pathogenesis of some viruses, such as HIV, HBV, $\mathrm{HCV}$, and RSV. However, to date, limited data are available on EV content/structure and role during infection with SARS-CoV-2. Moreover, the roles of EVs in immune suppression and regulation, antigen presentation, and inflammation have not yet been fully elucidated. In the current work, we have used isolated EVs to perform untargeted metabolomics to identify key metabolites and associated pathways that are present in COVID-19 patients and could be developed as a therapeutic/diagnostic target.

\section{Results}

\subsection{Demographics of the Study Population}

The study population included nine subjects equally allocated into the following three groups: control (uninfected), mild to severe COVID-19 cases, and severe-ICU COVID-19 cases (Table 1). The mean ages of control subjects, mild-severe, and severe-ICU COVID-19 patients were $30.33 \pm 2.40,54.33 \pm 3.93$, and $59.33 \pm 7.69$ years, respectively. Table 1 also shows the main medication used to treat each COVID-19 patient.

Table 1. Demographic data for COVID-19 patients ( $n=3$ /group) and healthy control subjects $(n=3)$.

\begin{tabular}{cccc}
\hline Group & Age & Gender & Main Medication(s) \\
\hline Control & $30.33 \pm 2.40$ & $3 \mathrm{M}$ & $\begin{array}{c}\text { Favipravir, Ceftriaxone, Azithromycin, } \\
\text { Foscarnet, Indinavir, Lymecycline } \\
\text { Dexamethasone, and Clexane }\end{array}$ \\
Sild-Severe & $54.33 \pm 3.93$ & $1 \mathrm{M}, 2 \mathrm{~F}$ & $\begin{array}{c}\text { Favipravir, Ceftriaxone, Azithromycin, } \\
\text { Foscarnet, Indinavir, and Lymecycline }\end{array}$ \\
\hline
\end{tabular}

M: Male and F: female.

\subsection{Characterization of Isolated Exosomes}

TEM examination for EVs extracted from the serum of COVID-19 patients and healthy controls revealed the presence of nanovesicles of different sizes (Figure 1A,B). The size of these exosomes ranged from 90 to $250 \mathrm{~nm}$ in diameter, as detected by NanoSight (Figure 1C).

\subsection{Metabolomics of COVID-19 Patients' and Healthy Individuals' EVs}

To assess whether EV-associated metabolites correlate with various traits of COVID19, we performed untargeted metabolomics in isolated EVs of COVID-19 patients and compared it with healthy individuals by using LC-MS/MS. After the initial runs, all the raw files were analyzed by using XCMS software for feature detection and their total ion chromatograms were merged and visualized (Figure 2A). 

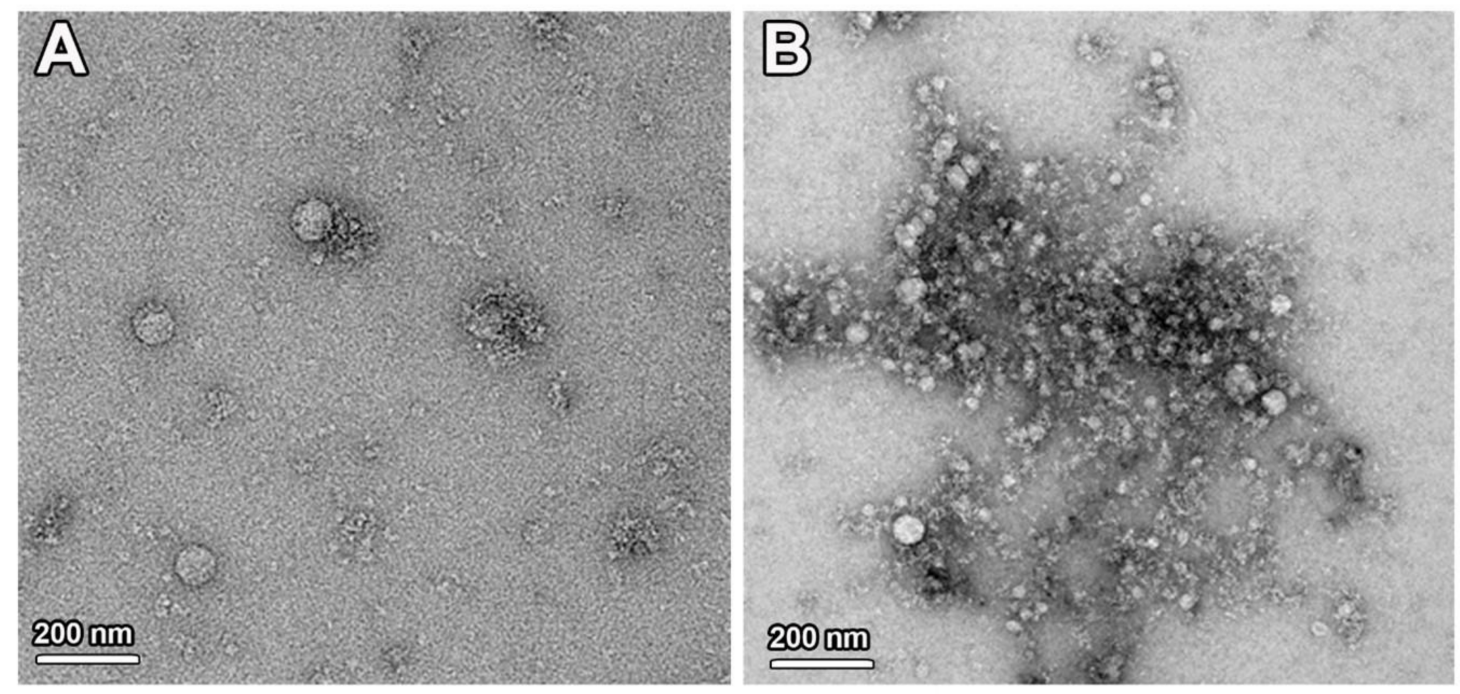

G
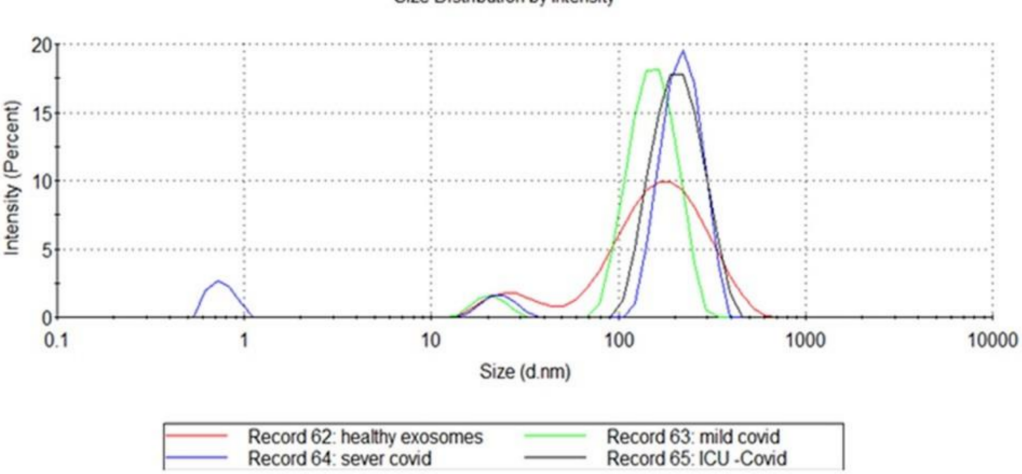

Figure 1. Characterization of isolated exosomes from control and patient samples. TEM examination shows MVs in serum samples isolated from the healthy controls (A) and COVID-19 patients (B). (C) NanoSight graph shows average size of the isolated exosomes.
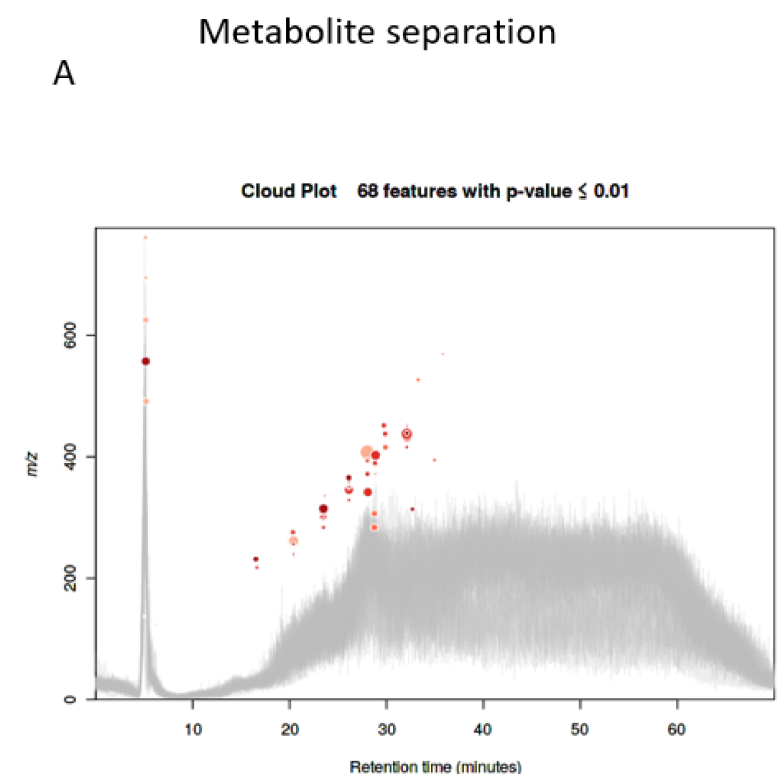
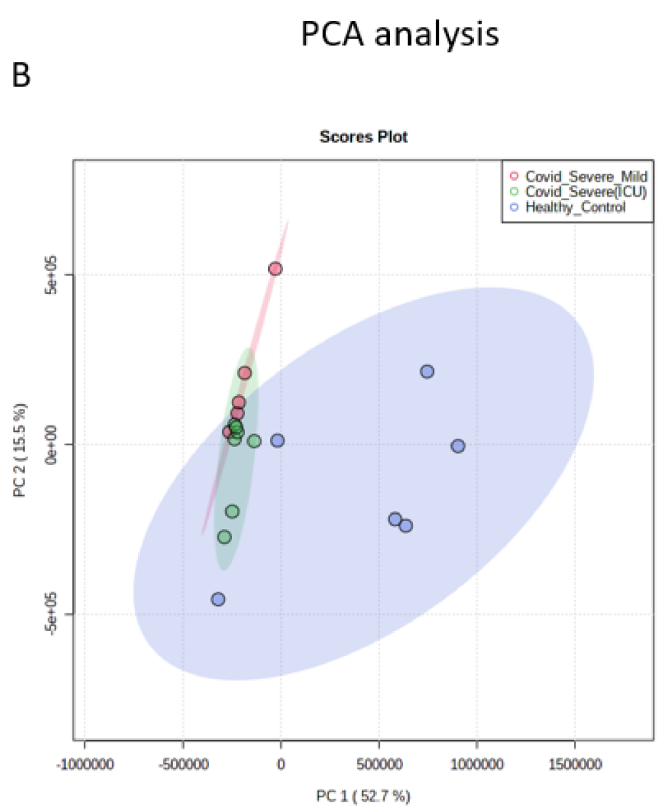

Figure 2. Metabolite separation and statistical analysis. (A) Total ion chromatogram of EVs isolated from both healthy and COVID-19 patient samples. (B) Scores plot between the healthy and COVID-19 patient samples. The explained variances are shown in brackets. 
After analyzing the feature peaks, a total of 163 rationally adjusted circulating metabolite features were identified in the EV concentrates by using the $\mathrm{ESI}^{+}$mode (Supplementary Table S1). Further, two-dimensional principal component analysis (2D-PCA) model score plots of all samples showed no outliers and simultaneously revealed a significant difference in metabolites between the COVID 19 patients and healthy control individuals (Figure 2B).

\subsection{Differential Metabolites in COVID-19 EVs}

Among the total number of rationally adjusted EV metabolites in this study, 95 metabolites were found to be significantly $(p<0.05)$ modulated: either up- or down-regulated in COVID-19 patients when compared with healthy controls. Among these identified metabolites, 29 (upregulated) and 66 (downregulated) were found to be statistically significant in COVID-19 patients' EVs when compared with healthy control EVs (Supplementary Table S2). Next, we plotted metabolites based on self-correlations by using the total number of rationally adjusted metabolites and found a significant correlation coefficient among the identified metabolites (Figure 3A). Further, using the total number of rationally adjusted metabolites, we created a hierarchical cluster analysis (HCA) heatmap and found that the COVID-19 patient samples were well-clustered separately from healthy controls (Figure 3B).

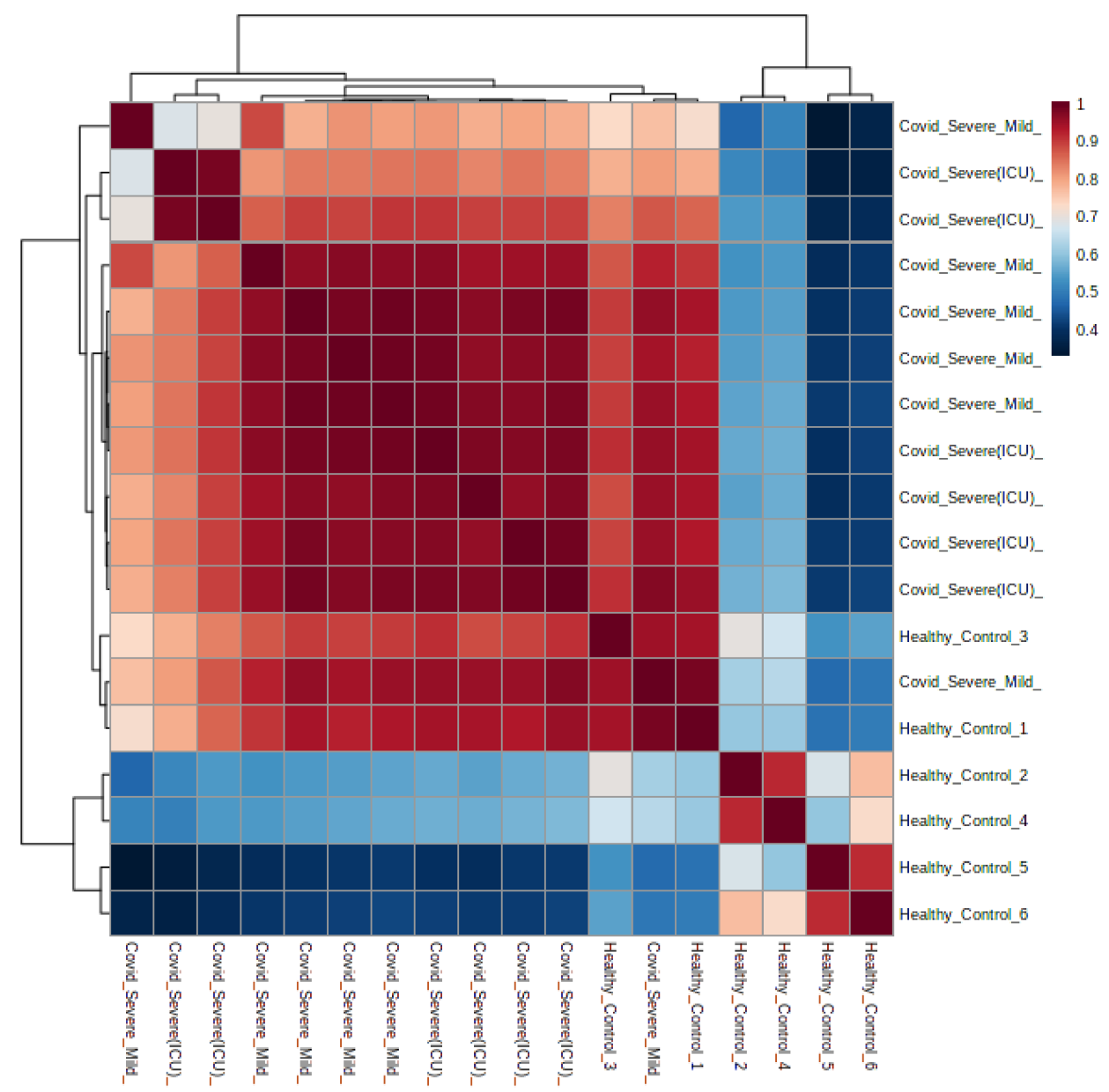

(A)

Figure 3. Cont. 


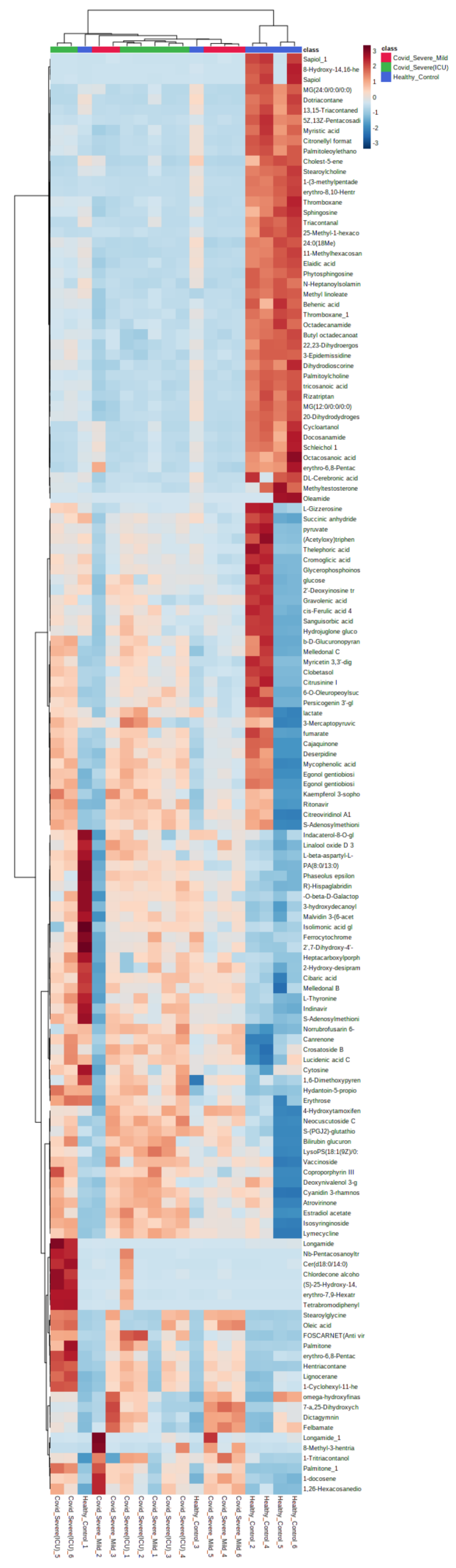

(B)

Figure 3. Correlation and expression of identified metabolites from both control and patient samples. (A) Correlation analysis of differentially modulated metabolites identified in both healthy and COVID-19 patient samples. (B) Clustering result is shown as a heatmap (distance measure using Euclidean distance and clustering algorithm using Ward heat map of individual samples). 


\subsection{Pathway Enrichment Analysis of Identified Metabolites in EVs}

To identify pathways that are associated with identified metabolites in EVs of COVID19 patients, we used the well-established MetaboAnalystR version 3.0. Results showed that EV-associated metabolites were associated with many important metabolic pathways, such as the glucose-alanine cycle, methyl histidine metabolism, spermidine, and spermine biosynthesis, gluconeogenesis, phosphatidylcholine biosynthesis, alanine, and sphingolipid metabolism (Figure 4A). We further extended to build a lipid-based pathway that was identified in EVs. As shown in Figure 4B, different classes of lipids were enriched, and among them the highest were the fatty acids and conjugates, suggesting their pivotal role in COVID-19 pathophysiology.

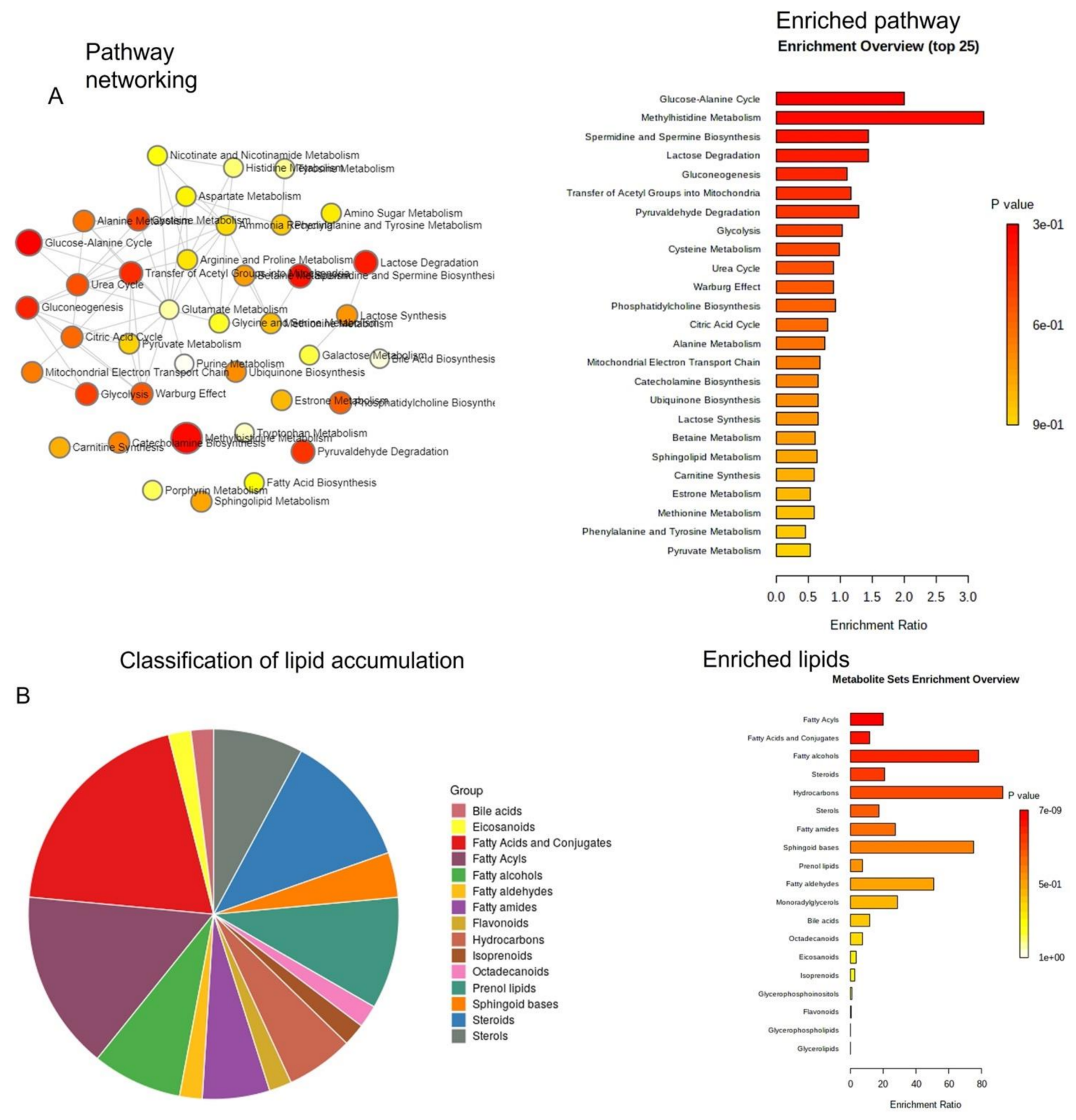

Figure 4. (A,B) Metabolite enrichment analysis: pathway networking, enriched pathways, and classification of accumulated lipid classes found in healthy control and COVID-19 patient EVs. 
Upon segregating the statistically significant metabolites that are upregulated, we noticed that EVs from COVID-19 carry a variety of antivirals and antibiotics, such as Foscarnet, Indinavir, and lymecycline, that were almost absent in the control EVs (Figure 5A). We found increased levels of Stearoylglycine, an acylglycine with C-18 fatty acid group, as the acyl moiety. The acylglycines class of fatty acid metabolites associated with patients with various fatty acid oxidation disorders. Further, we observed significantly high levels of oleic acid (fatty acid) in EVs of COVID-19 patients when compared to healthy EVs (Figure 5B). Next, we observed that COVID-19 EVs contain increased levels of conjugated bilirubin metabolites, namely bilirubin glucuronide and estradiol acetate glucuronide, when compared to EVs of healthy individuals. Surprisingly, we detected an increased amount of Coproporphyrin III (a porphyrin metabolite arising from heme synthesis), known to be elevated during viral infections, in EVs of COVID-19 patients (Figure 5C).
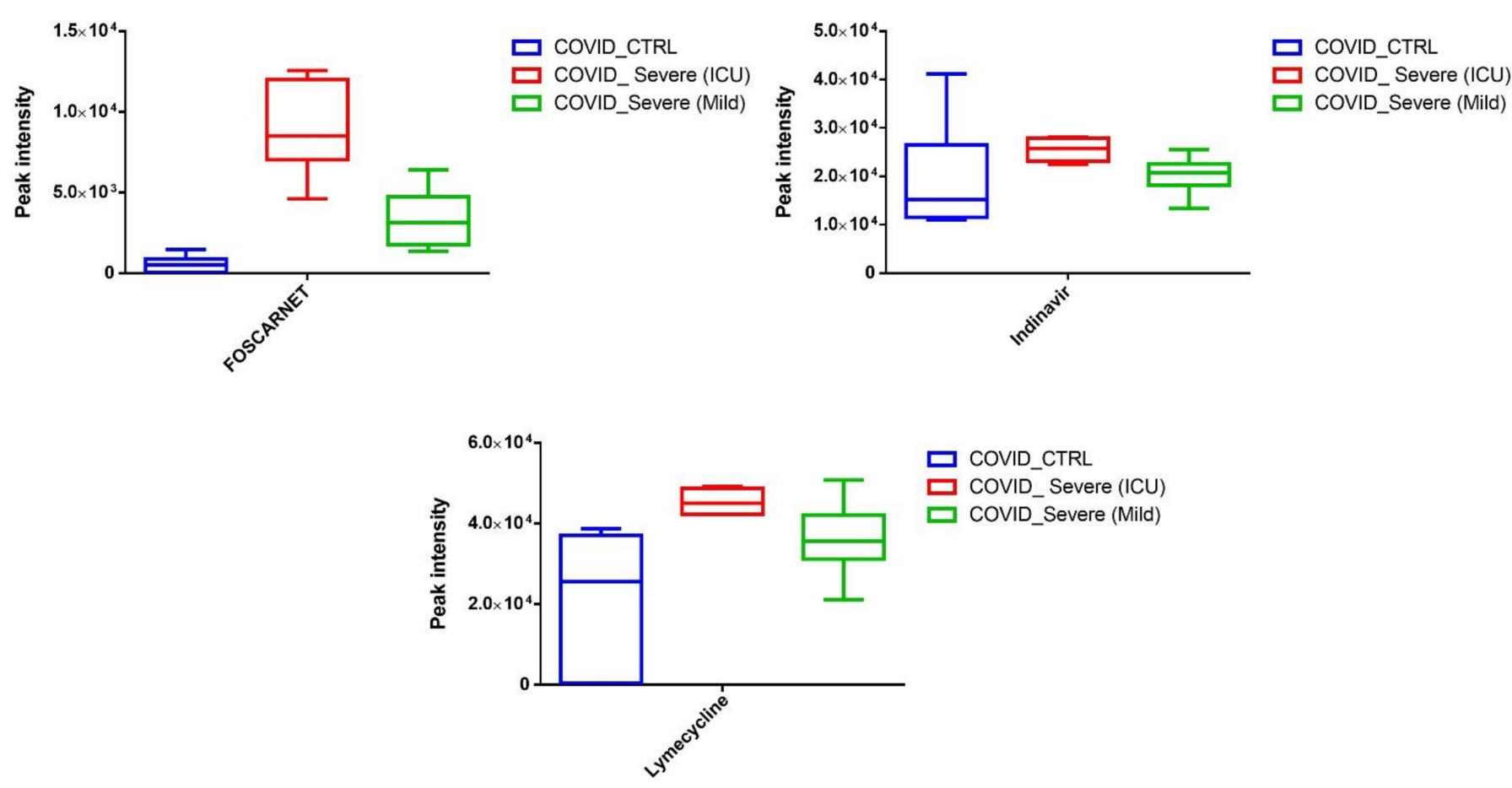

(A)
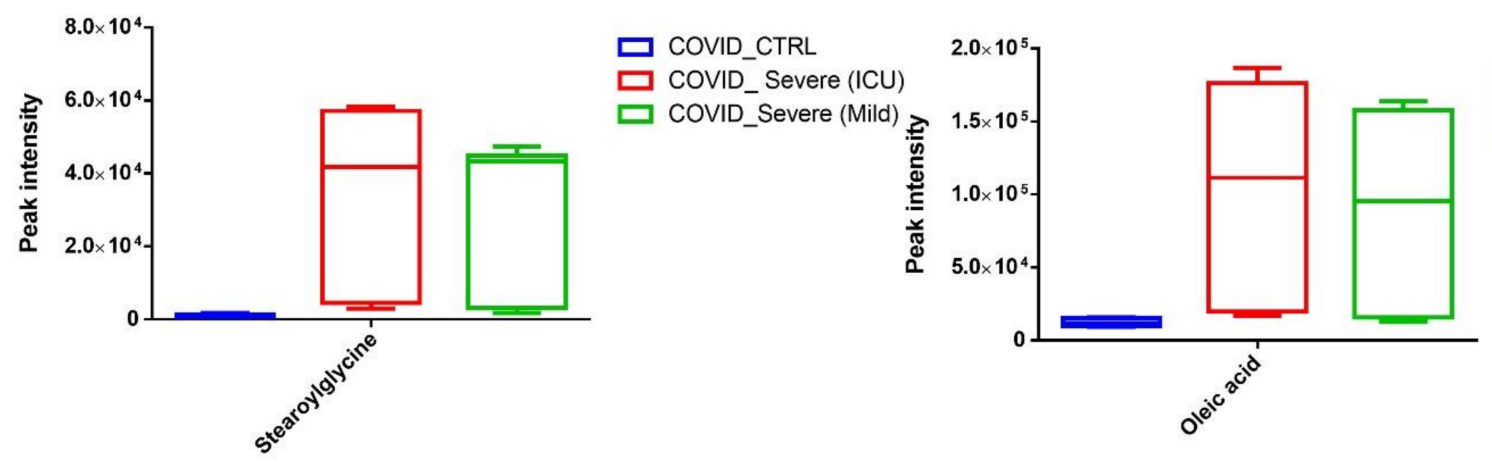

$\square$ COVID_CTRL

$\square$ COVID_Severe (ICU)

$\square$ COVID_Severe (Mild)

(B)

Figure 5. Cont. 


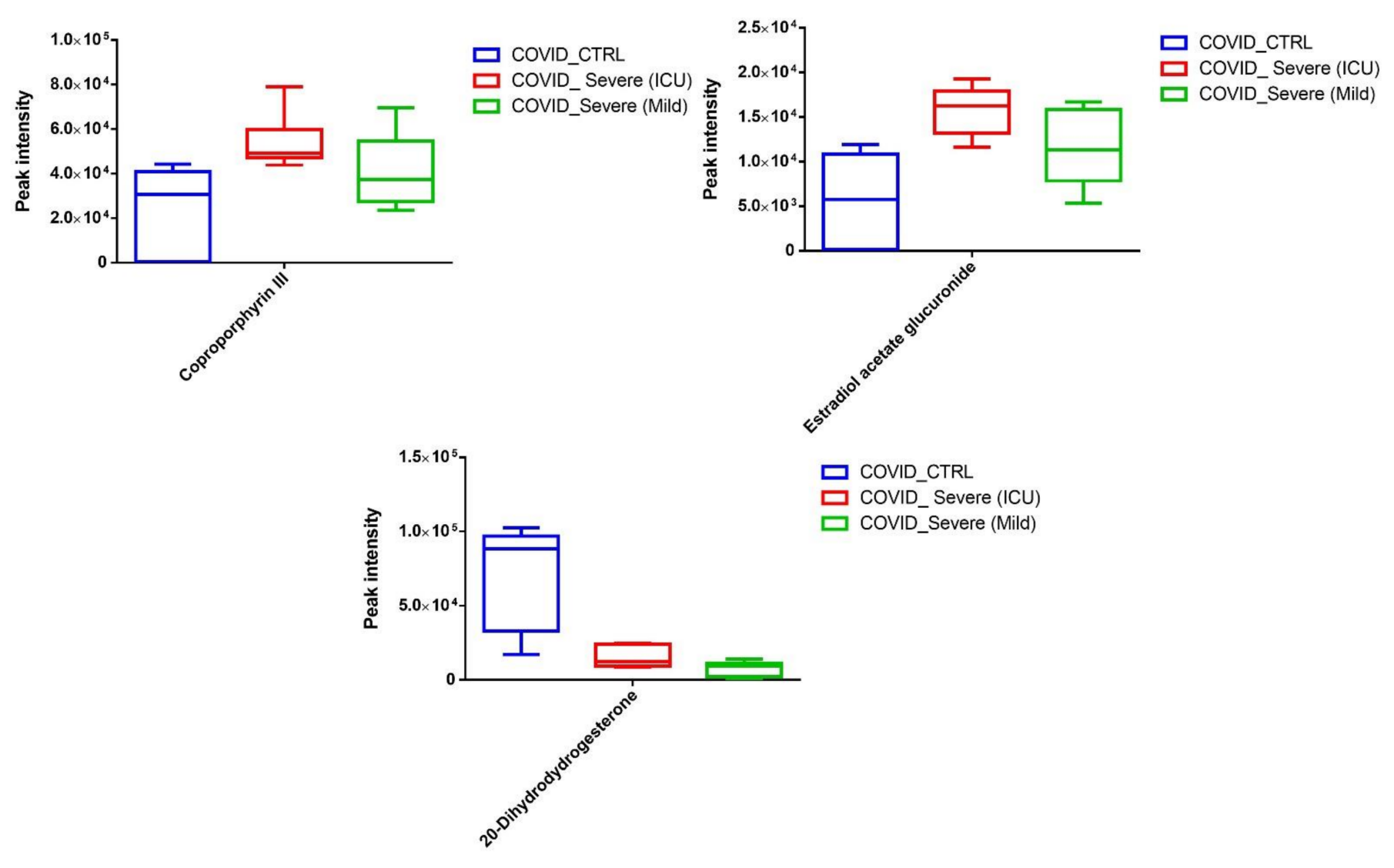

(C)

Figure 5. (A-C) Quantitative levels of statistically significant metabolites $(p<0.01)$ found to be upregulated in COVID-19 EVs when compared to healthy samples. Data are presented as box plot, median, and interquartile range $(n=3 /$ group).

In addition to the above-mentioned results, we noticed induction of three major metabolites that are directly related to the resolution of various inflammatory pathways. We observed increased levels of LysoPS (18:1, a lysophospholipid), 7- $\alpha, 25$-Dihydroxycholesterol (an endogenous ligand for EBI2 receptor on immune cells), and 15-d-PGJ2 (a ligand for the nuclear receptor PPAR $\gamma$ ) (Figure 6).

Next, we segregated the statistically significant downregulated EV-associated metabolites and identified thromboxane (a coagulant factor), elaidic acid (an unsaturated fatty acid that has been shown to modulate inflammatory responses), and palmitoylcholine (a phospholipid that plays a crucial role in cell signaling and communication). Further, we observed a significant decline in 20-Dihydrodydrogesterone (DHD), known to modulate endothelial nitric oxide, in EVs of COVID-19 patients when compared to EVs of healthy controls (Figure 7). In addition, we also noticed a significant reduction in many metabolites whose systemic and physiological impacts are still not well-known (Supplementary Table S2). 

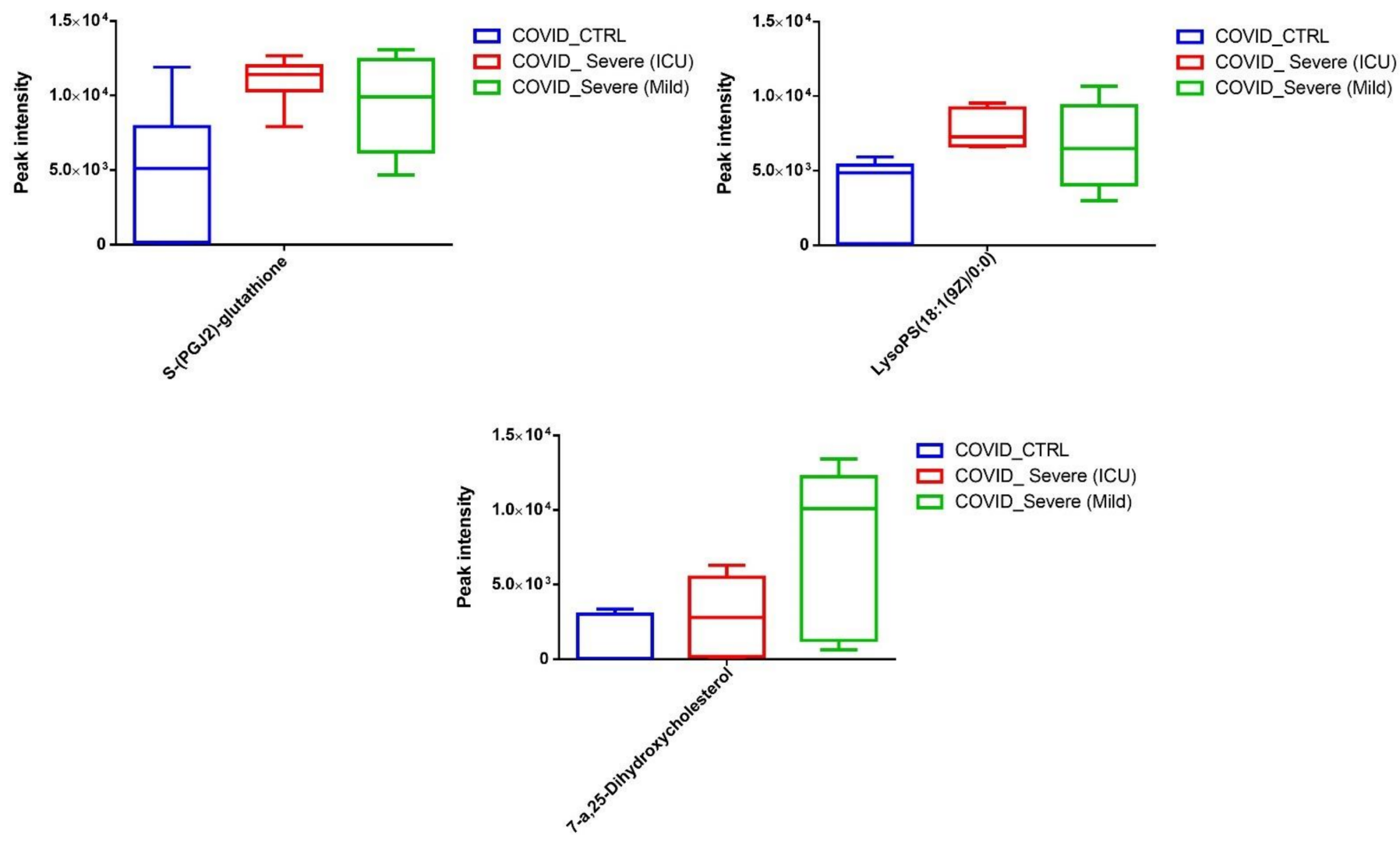

Figure 6. Quantitative levels of LysoPS, 7- $\alpha$,25-Dihydroxycholesterol, and 15-d-PGJ2 in COVID-19 EVs when compared to healthy control samples.
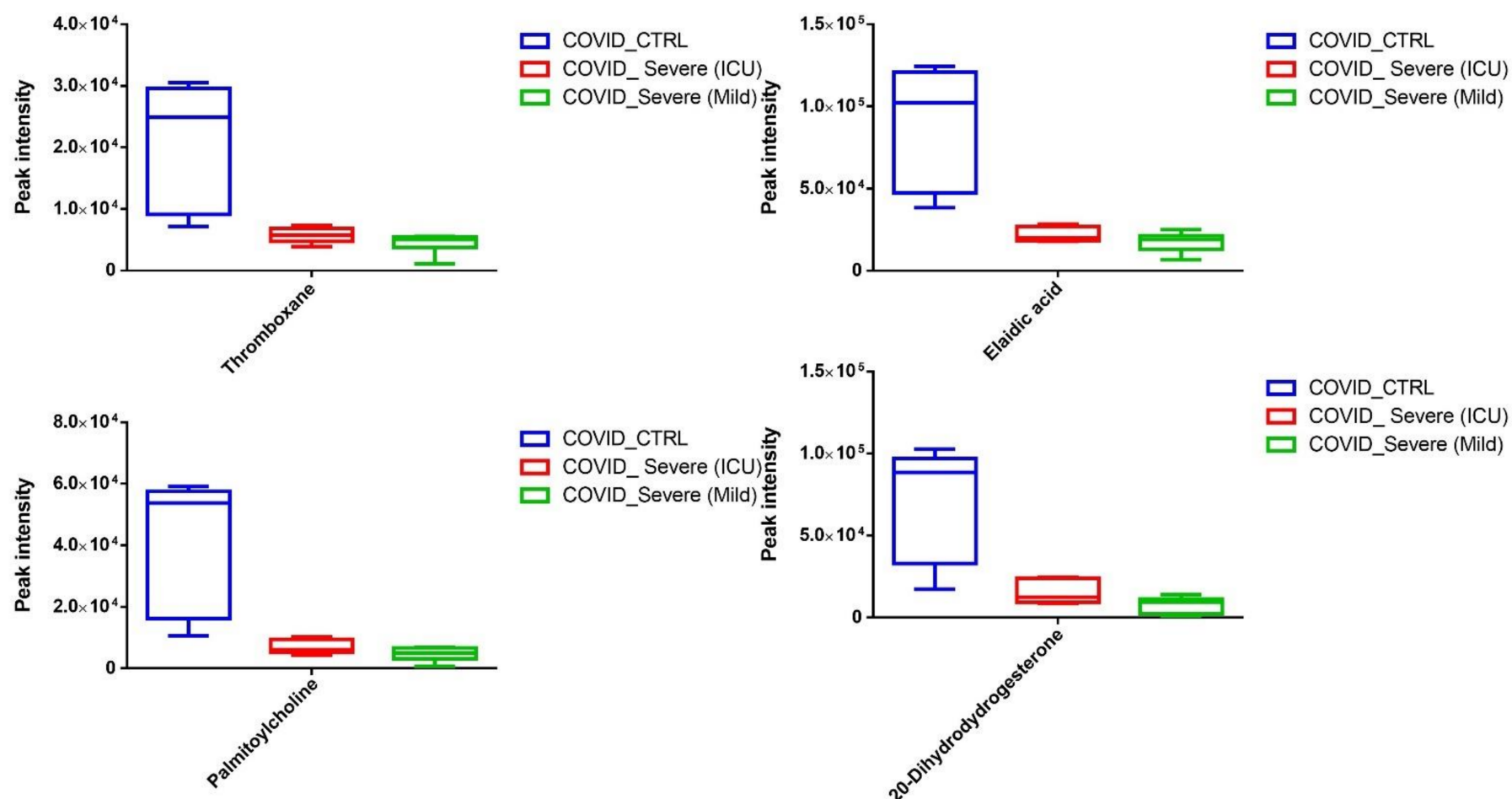

Figure 7. Quantitative level of statistically significant metabolites $(p<0.01)$ found to be downregulated in COVID-19 EVs when compared to healthy control samples. Data are presented as box plot, median, and interquartile range $(n=3 /$ group). 


\subsection{Screening for Identification of Potential COVID-19-Specific Metabolites in EVs}

Finally, we sought to learn whether any metabolite or group of metabolites might be considered as COVID-19-specific. For this, we performed the variable importance in projection (VIP) score, and $15 \mathrm{EV}$ metabolites were found to be responsive towards the variation between COVID-19 patient samples and healthy control samples (Figure 8). Among the metabolites that discriminated COVID-19 patient samples from healthy controls were four upregulated metabolites, namely oleic acid, 1,26-hexacosanediol, longamide, and dictagymnin, belonging to different metabolic pathways and suggesting a clear alteration in the respective pathways.

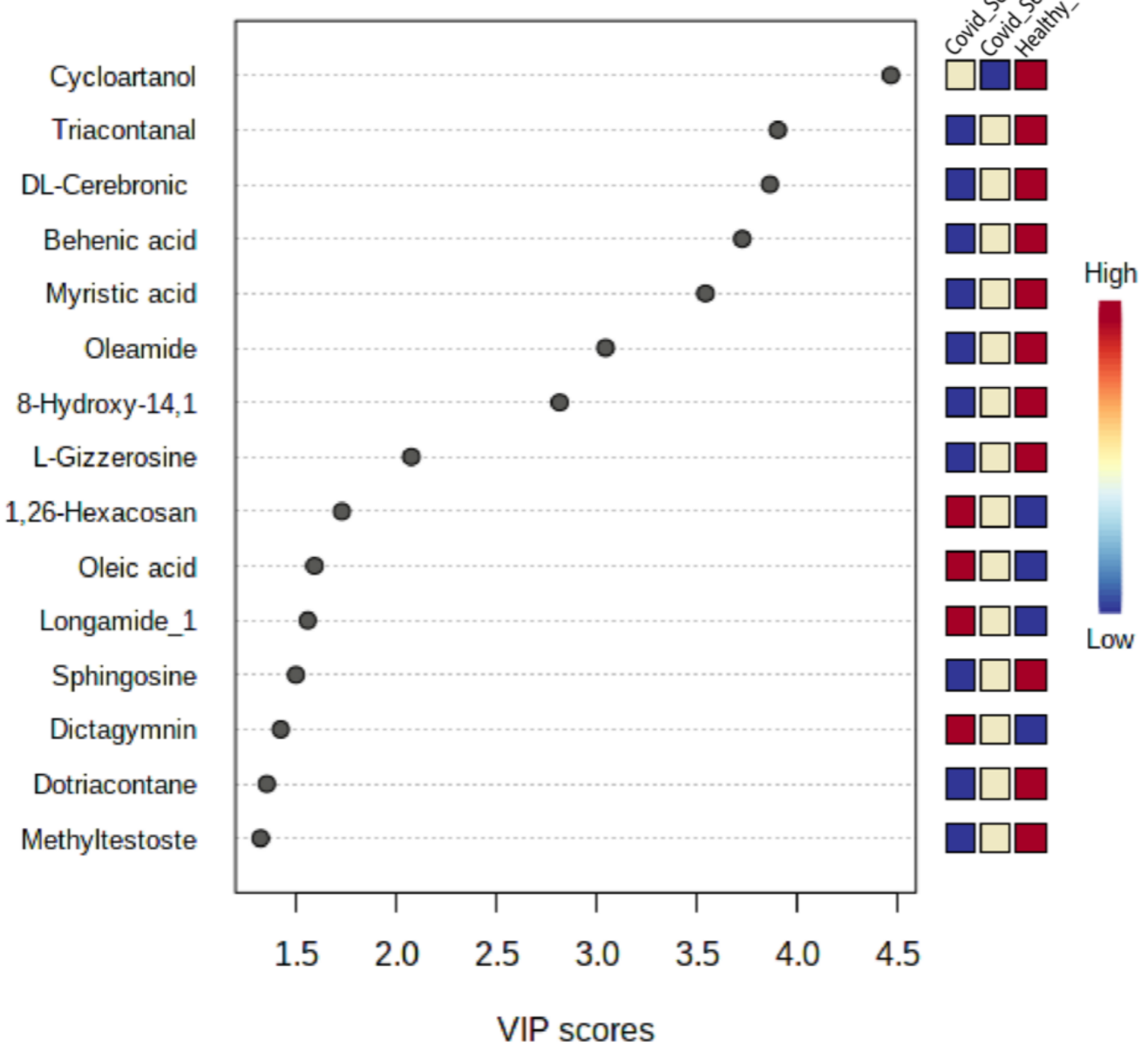

Figure 8. PLS-DA analysis for identification of crucial metabolites associated with disease. The colored boxes on the right indicate the relative concentration of the corresponding metabolites from EVs that are taken from both healthy and COVID-19 patient samples.

Similarly, downregulated metabolites DL-cerebronic acid, cycloartanol, behenic acid, oleic acid, and dotriacontane were only associated with EVs of COVID-19 patient samples. Based on these results, we have identified some potential candidate metabolites in EVs that can clearly discriminate COVID-19 patients from healthy controls and may be COVID-19specific metabolites.

\section{Discussion}

EVs such as exosomes can transport molecules derived from viruses, and some reports suggest that they regulate host immune response in a way that enables the virus to evade the immune system $[44,45]$. Recently, some viral RNAs were identified in exosomes derived 
from COVID-19 patients, suggesting the possibility of using these exosomes in SARSCoV-2 transmission within the host [40]. Moreover, exosomal microRNAs were found to play an important role in the formation of thrombi in COVID-19 patients [6]. Several recent studies addressed the ability of exosomes to transmit proteins and metabolites that could participate in virus transmission and severity [25,40-43]. However, little is known regarding the potential of EVs as carriers for anti-inflammatory and anti-viral metabolites and drugs with a prospective therapeutic role for EVs. Therefore, this study was conducted to unveil such therapeutic potential. Based on the results of the current work, we found: (1) that EVs from COVID-19 patients showed the presence of a variety of antivirals and antibiotics, such as Foscarnet, Indinavir, and lymecycline, (2) increased levels of antiinflammatory metabolites such as LysoPS, 7- $\alpha, 25$-Dihydroxycholesterol, and 15-d-PGJ2 in EVs from the sera of COVID-19 patients, and (3) decreased levels of metabolites associated with coagulation, such as thromboxane and elaidic acid, in exosomes from the sera of COVID-19 patients.

Our results postulated that sera exosomes orchestrated a regulatory mechanism for modulating the inflammatory storm and thrombosis during SARS-CoV-2 infection. We managed to identify a large pool of metabolites with a wide range of physiological actions in both healthy and disease conditions. However, here, we chose to focus only on the inflammatory pathway-associated metabolites, since inflammation plays a major role in COVID-19-related pathogenesis. Majority of the top enriched metabolites (95 metabolites $(p<0.05)$ modulated, either up- or down-regulated in COVID-19 patients when compared with healthy controls) were still not associated with the pathogenesis of COVID-19, clearly suggesting that future studies need to explore their exact role in the pathogenesis of COVID-19.

Firstly, we noticed that EVs from COVID-19 carry a variety of antivirals and antibiotics, such as Foscarnet, Indinavir, and lymecycline, that were almost absent in the control EVs. It is highly speculative that EVs are used to deliver these drugs to the target cells or organs, primarily to restrain COVID-19 pathogenesis. To the best of our knowledge, we are the first to report such findings related to exosomes in COVID-19 patients. This finding seems to be highly relevant as EVs are known to serve as natural carriers for small molecules, drugs, and vaccine candidates for therapy [46-49]. However, further research work will provide a clearer picture of the above-mentioned findings.

Among the many significantly increased metabolites, we were highly interested in LysoPS, 7- $\alpha$,25-Dihydroxycholesterol, and 15-d-PGJ2, which have a defined role in immunity and inflammation. Lysophosphatidylserine (LysoPS) is a well-known monoacyl derivative of phosphatidylserine (diacylPS), and possesses unique signaling characteristics important in acute inflammation and the orchestration of its resolution. Broadly, LysoPS has long been known as a signaling phospholipid in mast cell biology, enhancing histamine release and eicosanoid production. Further, there has been a resurgence of interest in LysoPS as it plays a crucial role in the resolution of inflammation by promoting efferocytosis [50-52]. Oxidant-derived LysoPS from neutrophils is known to be an endogenous anti-inflammatory mediator, mediating the "early" and rapid clearance of localized neutrophils [53]. LysoPS was found to block the activation of T cells via its interaction with its cognate receptor GPR174 to suppress IL-2 production by activated T cells and limit upregulation of the activation markers CD25 and CD69 [54]. We believe that EVs use LysoPS for constraining the local inflammation by neutralizing the activation of various immune cells, e.g., T cells, neutrophils, and mast cells, along with suppression of inflammatory cytokines [55] in targeted tissues during COVID-19 infection. However, this claim requires proper experimental validation.

7- $\alpha, 25$-Dihydroxycholesterol $(7 \alpha, 25-\mathrm{OHC})$, an oxysterol, binds to EBI2 on immune cells. Recently published studies elucidated that $7 \alpha, 25-\mathrm{OHC}$ bound to EBI2 regulates migration, activation, and functions of B cells, T cells, dendritic cells (DCs), monocytes/macrophages, and astrocytes [56]. In the majority of cell types, $7 \alpha, 25-\mathrm{OHC}$ is derived from 25 - hydroxycholesterol $(25-\mathrm{HC})$ and possesses broad inhibitory activities against enveloped viruses of 
different families [57-59]. Though 25-HC has clearly shown strong antiviral activity against COVID-19 [60], direct evidence for the antiviral activity of its derivative $7 \alpha, 25-\mathrm{OHC}$ is still lacking and requires further investigation. Nonetheless, our data suggest that EVs carry $7 \alpha, 25-\mathrm{OHC}$ to position the B cells' response in the target tissue and to block viral replication during COVID-19 infection.

Finally, we discuss 15-d-PGJ2, a potent and natural ligand of peroxisome proliferatoractivated receptor-gamma (PPAR- $\gamma$ ), a member of the PPAR transcription factor family. Both natural (edible sources) and synthetic PPAR- $\gamma$ agonists (e.g., rosiglitazone and pioglitazone) are considered to be one of the most promising candidates to improve the clinical outcome of viral diseases. These PPAR- $\gamma$ agonists not only regress the inflammatory response to viral pneumonia but are also shown to promote the survival of influenzainfected mice [61-64]. For COVID-19-associated cytokine storm, PPAR- $\gamma$ agonists are also in consideration [65].

\section{Materials and Methods}

\subsection{Sampling, Ethical Aspects, and Patients}

Samples were obtained from multi-ethnicity patients or donors residing in Saudi Arabia. All samples from COVID-19 patients were collected from individuals admitted to the hospital, based on meeting COVID-19 case definition as per the Saudi Ministry of Health $(\mathrm{MOH})$ guidelines and confirmed by the RT-qPCR assay targeting the envelope (E) and RNA-dependent RNA polymerase (RdRp) genes. All samples were anonymized and used based on ethical approval obtained from the Unit of Biomedical Ethics in King Abdulaziz University Hospital (Reference No. 280-20) and the Institutional Review Board at the Ministry of Health, Saudi Arabia, with informed consent obtained from all participants. All methods and experiments were performed in accordance with the relevant guidelines and regulations. All healthy volunteers were confirmed with a PCR test and an antibody test to ensure that there was no history of infection. All the COVID-19 patients' $(n=6,3$ in each group) and healthy controls' $(n=3)$ samples were taken to KAU hospital between 1 July and 30 October 2020. In all cases, the included patients received the basic routine medical support established by the KAU hospital, that included the use of antibiotics, antivirals, vasopressor, anticoagulants, oxygen support, mechanic ventilation, and use of corticoids if necessary. The inclusion criteria included COVID-19 patients with mild to severe symptoms, while the exclusion criteria included COVID-19 patients without cancer or other viral infections such as HBV, HCV, HIV, and RSV.

The patients were divided into 2 groups, based on the course of the disease, as follows: the mild-severe group, which included patients with mild to severe symptoms that were discharged without admission to an ICU, and the severe-ICU group, which included patients with severe symptoms that were discharged after admission to an ICU. Healthy controls were randomly selected with no infection or other major diseases.

\subsection{Exosomes Concentration and Characterization}

At the time of hospital admission, blood samples were collected in vacutainer plain tubes for laboratory analyses. Serum was centrifuged at $3000 \times g$ for $15 \mathrm{~min}$ to remove cells and cell debris. The supernatant was then filtered through a $0.42 \mu \mathrm{m}$ filter and incubated with ExoQuick (SBI CAT No. EXOQ20A-1, Embarcadero Way, Palo Alto, Canada) according to the manufacturing guide. Pellets were then resuspended in PBS and stored at $-80{ }^{\circ} \mathrm{C}$ in a freezer. Nanoparticle tracking analysis (NTA) was used to count and size nanoparticles in suspension. Briefly, $10 \mu \mathrm{L}$ of EXO suspension was loaded into the sample chamber of a Zetasizer Nano ZS90 (Malvern Panalytical, Malvern, U.K). Data analysis was performed using NTA software, version 3.3 (Malvern Panalytical, England). Transmission electron microscopy (TEM) was used to examine the morphology of the exosomes. Exosomes were fixed with $2.5 \%$ glutaraldehyde, then a drop of exosomes $(10 \mu \mathrm{L})$ was added to a grid. All excess fluid was removed using filter paper, and the samples were negatively stained using 
an aqueous $1 \%$ phosphotungstic acid with $\mathrm{pH} 7.2$. The samples were then air-dried and viewed using an electron microscope Titan CT_iac (FEI, Titan D3187).

\subsection{Untargeted Metabolomics of EVs}

\subsubsection{Metabolite Extraction}

Extraction of metabolites from EVs was performed by adding some modifications to the pre-established protocols of our group [66-68], and untargeted metabolomics was performed using HPLC-tandem mass spectrometry (LC-MS/MS). All samples from each participant were analyzed in triplicate. Briefly, $400 \mu \mathrm{L}$ of extracting solvent was mixed in ice-cold methanol:acetonitrile:chloroform:water at a ratio of 2:2:2:1 $(v / v)$, added to the exosomes, followed by vortexing and incubation for an hour at $-20{ }^{\circ} \mathrm{C}$. Further, samples were then spun at $4{ }^{\circ} \mathrm{C}$ for $5 \mathrm{~min}$ at $8000 \mathrm{rpm}$, and supernatants were collected. Supernatant samples were analyzed using LC-MS/MS.

\subsubsection{HPLC Workflow}

HPLC-based separation was performed with some modifications to the pre-established protocol: $10 \mu \mathrm{L}$ of metabolite extract was injected into a HPLC column (Hypersail gold column C18 Part No: 25005-104630; $100 \times 4.6 \mathrm{~mm}, 5 \mu \mathrm{m})$ with a flow rate of $0.25 \mathrm{~mL} / \mathrm{min}$. The mobile phase consisted of $0.1 \%$ formic acid and $99.9 \%$ ACN formic acid $(0.1 \%, v / v)$, using a gradient program, where the component of solution was changed from $5 \%$ to $30 \%$ for $30 \mathrm{~min}, 30 \%$ to $50 \%$ for $10 \mathrm{~min}, 50 \%$ for $10 \mathrm{~min}$, and finally, 50\% to $95 \%$ for $20 \mathrm{~min}$, at a constant flow rate, with a total running time of $70 \mathrm{~min}$. The column temperature was maintained at $30{ }^{\circ} \mathrm{C}[69]$.

\subsubsection{Mass Spectrometry Parameters}

A LTQ XL ${ }^{\mathrm{TM}}$ linear ion trap instrument (Thermo Fisher Scientific, USA) was used for the untargeted metabolomic analysis. Full scan scope was chosen from 80 to $1000 \mathrm{~m} / \mathrm{z}$. The spray voltage was set at $-3.0 \mathrm{kV}$. The capillary voltage was fixed at $4.0 \mathrm{~V}$ and the temperature was set at $270{ }^{\circ} \mathrm{C}$, collision energy 40 arbitrary units. Nitrogen was used as a sheath gas and the flow rate was set at 40 arbitrary units. Further, helium was used as the buffer gas for the run $[70,71]$.

\subsubsection{Data Processing}

The raw file data obtained from LTQ-XL were converted into mzXML using raw converter software. The mzXML files were processed using XCMS (https:/ / xcmsonline. scripps.edu (accessed on 24 September 2021)) for feature detection, retention time correction, and alignment. The parameters in XCMS were set as follows: Cent-Wave settings for feature detection $(\Delta m / z=30 \mathrm{ppm}$, minimum peak width $=10 \mathrm{~s}$, and maximum peak width $=120 \mathrm{~s})$ and $m / z$ wid $=0.25$, min frac $=0.5$, and $\mathrm{bw}=10$ for chromatogram alignment. After careful evaluation of the retention time, alignment was shown to not be required. Isotopic peaks and adducts were detected using a camera. The precursor was matched with the METLIN database at 20 ppm accuracy.

\subsubsection{Metabolomics Pathway Analysis}

The web-based R-package MetaboAnalyst 3.0 (https: / www.metaboanalyst.ca/faces / home.xhtml (accessed on 24 September 2021)) was used to analyze metabolomics pathways [72].

\subsection{Statistical Analysis}

Statistical and chemometric analyses were performed as previously described [68]. Kruskal-Wallis non-parametric analysis was performed. Datasets were presented as box plot, median, and interquartile range. Statistical significance was defined as $p \leq 0.05$. 


\section{Conclusions}

Overall, our extensive untargeted metabolomic approach identified that exosomes not only carry active drug molecules but also anti-inflammatory metabolites, clearly suggesting that exosomes play a crucial role in negotiating with heightened inflammation during COVID-19 infection. However, one major limitation of our work is that we did not perform any functional validation regarding the anti-inflammatory activity of the three major metabolites during COVID-19 infection. We strongly believe that more future work will highlight the importance of exosomes as potential biological entities for the resolution of inflammation during COVID-19.

Supplementary Materials: The following are available online at https://www.mdpi.com/article/10 .3390/ijms221910467/s1.

Author Contributions: F.A.A., S.A., E.I.A., and M.R.S.M. contributed to acquisition and analysis of the data; F.A.A., M.I.K., T.A.M., and M.A.E.-M. drafted the manuscript; Y.H., W.H.A., A.Y., A.A., and R.A. contributed to technical and material support; R.S.A., B.F., B.K., and H.A. contributed to critical revision of the manuscript for important intellectual content. All authors contributed to the article. All authors have read and agreed to the published version of the manuscript.

Funding: The authors acknowledge the financial support provided by King Abdulaziz City for Science and Technology (General Directorate for Research \& Innovation Support) (GDRIS) (King Abdulaziz University). This work was conducted through the fast-track program for COVID-19 Research, Project No. 0067-009-01-20-5.

Institutional Review Board Statement: All samples were anonymized and used based on ethical approval obtained from the Unit of Biomedical Ethics in King Abdulaziz University Hospital (Reference No. 280-20) and the Institutional Review Board at the Ministry of Health, Saudi Arabia, with informed consent obtained from all participants.

Informed Consent Statement: Informed consent was obtained from all subjects involved in the study.

Acknowledgments: We extend our sincere thanks to both the Infectious Diseases Departments, King Abdulaziz University Hospital and East Jeddah Hospital, for their assistance in collecting patient samples. We extend our gratitude to the Core Metabolomics Facility, Department of Biochemistry, Faculty of Science, KAU, and the Central Laboratory of King Abdullah University of Science and Technology. We also extend our sincere thanks to the Immunology unit at the King Fahd Center for Medical Research. Additionally, we would like to thank King Faisal Specialist Hospital and Research Center, Jeddah, for their technical support (IRB approval No: 2020-47). Thanks are also extended to Moulay Mohammed, Faris Arar, Fadwa Al-Otaibi, Noor Bin Zaqer, and Eman Alghmadi for their assistance. Finally, a special thanks goes to the project consultant, Kenneth Witwer.

Conflicts of Interest: The authors declare that there is no conflict of interest regarding the publication of this article.

\section{References}

1. Zhou, P.; Yang, X.L.; Wang, X.G.; Hu, B.; Zhang, L.; Zhang, W.; Si, H.R.; Zhu, Y.; Li, B.; Huang, C.L.; et al. A pneumonia outbreak associated with a new coronavirus of probable bat origin. Nature 2020, 579, 270-273. [CrossRef]

2. Prompetchara, E.; Ketloy, C.; Palaga, T. Immune responses in COVID-19 and potential vaccines: Lessons learned from sars and mers epidemic. Asian Pac. J. Allergy Immunol. 2020, 38, 1-9. [PubMed]

3. Hoffmann, M.; Kleine-Weber, H.; Schroeder, S.; Kruger, N.; Herrler, T.; Erichsen, S.; Schiergens, T.S.; Herrler, G.; Wu, N.H.; Nitsche, A.; et al. SARS-CoV-2 cell entry depends on ACE2 and TMPRSS2 and is blocked by a clinically proven protease inhibitor. Cell 2020, 181, 271-280.e278. [CrossRef] [PubMed]

4. Coutard, B.; Valle, C.; de Lamballerie, X.; Canard, B.; Seidah, N.G.; Decroly, E. The spike glycoprotein of the new coronavirus 2019-ncov contains a furin-like cleavage site absent in cov of the same clade. Antivir. Res. 2020, 176, 104742. [CrossRef] [PubMed]

5. Ma, Y.; Huang, Y.; Wang, T.; Xiang, A.P.; Huang, W. ACE2 shedding and furin abundance in target organs may influence the efficiency of SARS-CoV-2 entry. Open Bioinform. J. 2021, 14, 1-12. [CrossRef]

6. Gambardella, J.; Sardu, C.; Morelli, M.B.; Messina, V.; Castellanos, V.; Marfella, R.; Maggi, P.; Paolisso, G.; Wang, X.; Santulli, G. Exosomal micrornas drive thrombosis in COVID-19. medRxiv 2020. [CrossRef] 
7. Wu, C.; Zheng, M.; Yang, Y.; Gu, X.; Yang, K.; Li, M.; Liu, Y.; Zhang, Q.; Zhang, P.; Wang, Y.; et al. Furin, a potential therapeutic target for COVID-19. iScience 2020, 23, 101642. [CrossRef]

8. Shang, J.; Ye, G.; Shi, K.; Wan, Y.; Luo, C.; Aihara, H.; Geng, Q.; Auerbach, A.; Li, F. Structural basis of receptor recognition by sars-cov-2. Nature 2020, 581, 221-224. [CrossRef]

9. Tai, W.; He, L.; Zhang, X.; Pu, J.; Voronin, D.; Jiang, S.; Zhou, Y.; Du, L. Characterization of the receptor-binding domain (rbd) of 2019 novel coronavirus: Implication for development of rbd protein as a viral attachment inhibitor and vaccine. Cell Mol. Immunol. 2020, 17, 613-620. [CrossRef] [PubMed]

10. Inchingolo, A.D.; Inchingolo, A.M.; Bordea, I.R.; Malcangi, G.; Xhajanka, E.; Scarano, A.; Lorusso, F.; Farronato, M.; Tartaglia, G.M.; Isacco, C.G.; et al. SARS-CoV-2 disease adjuvant therapies and supplements breakthrough for the infection prevention. Microorganisms 2021, 9, 525. [CrossRef] [PubMed]

11. Alzahrani, F.A.; El-Magd, M.A.; Abdelfattah-Hassan, A.; Saleh, A.A.; Saadeldin, I.M.; El-Shetry, E.S.; Badawy, A.A.; Alkarim, S. Potential effect of exosomes derived from cancer stem cells and mscs on progression of den-induced hcc in rats. Stem Cells Int. 2018, 2018, 17. [CrossRef]

12. Badawy, A.A.; El-Magd, M.A.; AlSadrah, S.A. Therapeutic effect of camel milk and its exosomes on mcf7 cells in vitro and in vivo. Integr. Cancer Ther. 2018, 7, 1235-1246. [CrossRef]

13. Chen, J.; Xu, Q.; Zhang, Y.; Zhang, H. Rna profiling analysis of the serum exosomes derived from patients with chronic hepatitis and acute-on-chronic liver failure caused by hbv. Sci. Rep. 2020, 10, 1528. [CrossRef]

14. Devhare, P.B.; Sasaki, R.; Shrivastava, S.; Di Bisceglie, A.M.; Ray, R.; Ray, R.B. Exosome-mediated intercellular communication between hepatitis c virus-infected hepatocytes and hepatic stellate cells. J. Virol. 2017, 91, e02225-16. [CrossRef] [PubMed]

15. Alzahrani, F.A. Melatonin improves therapeutic potential of mesenchymal stem cells-derived exosomes against renal ischemiareperfusion injury in rats. Am. J. Transl. Res. 2019, 11, 2887-2907. [PubMed]

16. Ibrahim, H.M.; Mohammed-Geba, K.; Tawfic, A.A.; El-Magd, M.A. Camel milk exosomes modulate cyclophosphamide-induced oxidative stress and immuno-toxicity in rats. Food Funct. 2019, 10, 7523-7532. [CrossRef]

17. Chahar, H.S.; Corsello, T.; Kudlicki, A.S.; Komaravelli, N.; Casola, A. Respiratory syncytial virus infection changes cargo composition of exosome released from airway epithelial cells. Sci. Rep. 2018, 8, 387. [CrossRef]

18. Bukong, T.N.; Momen-Heravi, F.; Kodys, K.; Bala, S.; Szabo, G. Exosomes from hepatitis c infected patients transmit hcv infection and contain replication competent viral rna in complex with ago2-mir122-hsp90. PLoS Pathog. 2014, 10, e1004424. [CrossRef]

19. Urbanelli, L.; Buratta, S.; Tancini, B.; Sagini, K.; Delo, F.; Porcellati, S.; Emiliani, C. The role of extracellular vesicles in viral infection and transmission. Vaccines 2019, 7, 102. [CrossRef]

20. Lindenbach, B.D.; Evans, M.J.; Syder, A.J.; Wölk, B.; Tellinghuisen, T.L.; Liu, C.C.; Maruyama, T.; Hynes, R.O.; Burton, D.R.; McKeating, J.A. Complete replication of hepatitis c virus in cell culture. Science 2005, 309, 623-626. [CrossRef]

21. Yang, Y.; Han, Q.; Hou, Z.; Zhang, C.; Tian, Z.; Zhang, J. Exosomes mediate hepatitis b virus (hbv) transmission and nk-cell dysfunction. Cell. Mol. Immunol. 2017, 14, 465-475. [CrossRef]

22. Mason, R.J. Pathogenesis of covid-19 from a cell biology perspective. Eur. Respir. Soc. 2020, 55, 2000607. [CrossRef]

23. Farkash, E.A.; Wilson, A.M.; Jentzen, J.M. Ultrastructural evidence for direct renal infection with sars-cov-2. J. Am. Soc. Nephrol. 2020, 31, 1683-1687. [CrossRef] [PubMed]

24. Su, H.; Yang, M.; Wan, C.; Yi, L.-X.; Tang, F.; Zhu, H.-Y.; Yi, F.; Yang, H.-C.; Fogo, A.B.; Nie, X. Renal histopathological analysis of 26 postmortem findings of patients with covid-19 in china. Kidney Int. 2020, 98, 219-227. [CrossRef]

25. Sur, S.; Khatun, M.; Steele, R.; Isbell, T.S.; Ray, R.; Ray, R.B. Exosomes from covid- 19 patients carry tenascin-c and fibrinogen- $\beta$ in triggering inflammatory signals in distant organ cells. bioRxiv 2021. [CrossRef]

26. Chen, Y.M.; Zheng, Y.; Yu, Y.; Wang, Y.; Huang, Q.; Qian, F.; Sun, L.; Song, Z.G.; Chen, Z.; Feng, J. Blood molecular markers associated with covid-19 immunopathology and multi-organ damage. EMBO J. 2020, 39, e105896. [CrossRef]

27. Walsh, K.A.; Jordan, K.; Clyne, B.; Rohde, D.; Drummond, L.; Byrne, P.; Ahern, S.; Carty, P.G.; O’Brien, K.K.; O’Murchu, E. Sars-cov-2 detection, viral load and infectivity over the course of an infection: Sars-cov-2 detection, viral load and infectivity. $J$. Infect. 2020, 81, 357-371. [CrossRef]

28. Wang, J.; Chen, S.; Bihl, J. Exosome-mediated transfer of ace2 (angiotensin-converting enzyme 2) from endothelial progenitor cells promotes survival and function of endothelial cell. Oxidative Med. Cell. Longev. 2020, 2020, 4213541. [CrossRef]

29. Hassanpour, M.; Rezaie, J.; Nouri, M.; Panahi, Y. The role of extracellular vesicles in covid-19 virus infection. Infect. Genet. Evol. 2020, 85, 104422. [CrossRef]

30. Kissling, S.; Rotman, S.; Gerber, C.; Halfon, M.; Lamoth, F.; Comte, D.; Lhopitallier, L.; Sadallah, S.; Fakhouri, F. Collapsing glomerulopathy in a covid-19 patient. Kidney Int. 2020, 98, 228-231. [CrossRef]

31. Larsen, C.P.; Bourne, T.D.; Wilson, J.D.; Saqqa, O.; Moh'd, A.S. Collapsing glomerulopathy in a patient with covid-19. Kidney Int. Rep. 2020, 5, 935-939. [CrossRef]

32. Martines, R.B.; Ritter, J.M.; Matkovic, E.; Gary, J.; Bollweg, B.C.; Bullock, H.; Goldsmith, C.S.; Silva-Flannery, L.; Seixas, J.N.; Reagan-Steiner, S. Pathology and pathogenesis of sars-cov-2 associated with fatal coronavirus disease, united states. Emerg. Infect. Dis. 2020, 26, 2005. [CrossRef] [PubMed]

33. Menter, T.; Haslbauer, J.D.; Nienhold, R.; Savic, S.; Hopfer, H.; Deigendesch, N.; Frank, S.; Turek, D.; Willi, N.; Pargger, H. Postmortem examination of covid-19 patients reveals diffuse alveolar damage with severe capillary congestion and variegated findings in lungs and other organs suggesting vascular dysfunction. Histopathology 2020, 77, 198-209. [CrossRef] 
34. Deidda, M.; Noto, A.; Bassareo, P.P.; Cadeddu Dessalvi, C.; Mercuro, G. Metabolomic approach to redox and nitrosative reactions in cardiovascular diseases. Front. Physiol. 2018, 9, 672. [CrossRef] [PubMed]

35. Zhang, A.; Sun, H.; Yan, G.; Wang, P.; Wang, X. Metabolomics for biomarker discovery: Moving to the clinic. BioMed Res. Int. 2015, 2015, 354671. [CrossRef] [PubMed]

36. Mikami, T.; Aoki, M.; Kimura, T. The application of mass spectrometry to proteomics and metabolomics in biomarker discovery and drug development. Curr. Mol. Pharmacol. 2012, 5, 301-316. [CrossRef]

37. Memili, E.; Moura, A.A.; Kaya, A. Metabolomes of sperm and seminal plasma associated with bull fertility. Anim. Reprod. Sci. 2020, 220, 106355. [CrossRef]

38. Matthews, H.; Hanison, J.; Nirmalan, N. "Omics"-informed drug and biomarker discovery: Opportunities, challenges and future perspectives. Proteomes 2016, 4, 28. [CrossRef]

39. Szeremeta, M.; Pietrowska, K.; Niemcunowicz-Janica, A.; Kretowski, A.; Ciborowski, M. Applications of metabolomics in forensic toxicology and forensic medicine. Int. J. Mol. Sci. 2021, 22, 3010. [CrossRef]

40. Barberis, E.; Vanella, V.V.; Falasca, M.; Caneapero, V.; Cappellano, G.; Raineri, D.; Ghirimoldi, M.; De Giorgis, V.; Puricelli, C.; Vaschetto, R.; et al. Circulating exosomes are strongly involved in sars-cov-2 infection. Front. Mol. Biosci. 2021, 8, 29. [CrossRef]

41. Song, J.-W.; Lam, S.M.; Fan, X.; Cao, W.-J.; Wang, S.-Y.; Tian, H.; Chua, G.H.; Zhang, C.; Meng, F.-P.; Xu, Z. Omics-driven systems interrogation of metabolic dysregulation in covid-19 pathogenesis. Cell Metab. 2020, 32, 188-202.e185. [CrossRef]

42. Cocozza, F.; Névo, N.; Piovesana, E.; Lahaye, X.; Buchrieser, J.; Schwartz, O.; Manel, N.; Tkach, M.; Théry, C.; Martin-Jaular, L. Extracellular vesicles containing ace2 efficiently prevent infection by sars-cov-2 spike protein-containing virus. J. Extracell. Vesicles 2020, 10, e12050. [CrossRef]

43. Kumar, S.; Zhi, K.; Mukherji, A.; Gerth, K. Repurposing antiviral protease inhibitors using extracellular vesicles for potential therapy of covid-19. Viruses 2020, 12, 486. [CrossRef]

44. Kadiu, I.; Narayanasamy, P.; Dash, P.K.; Zhang, W.; Gendelman, H.E. Biochemical and biologic characterization of exosomes and microvesicles as facilitators of HIV-1 infection in macrophages. J. Immunol. 2012, 189, 744-754. [CrossRef]

45. Schorey, J.S.; Harding, C.V. Extracellular vesicles and infectious diseases: New complexity to an old story. J. Clin. Investig. 2016, 126, 1181-1189. [CrossRef] [PubMed]

46. Vader, P.; Mol, E.A.; Pasterkamp, G.; Schiffelers, R.M. Extracellular vesicles for drug delivery. Adv. Drug Deliv. Rev. 2016, 106, 148-156. [CrossRef] [PubMed]

47. Conlan, R.S.; Pisano, S.; Oliveira, M.I.; Ferrari, M.; Mendes Pinto, I. Exosomes as reconfigurable therapeutic systems. Trends Mol. Med. 2017, 23, 636-650. [CrossRef]

48. Ferguson, S.W.; Nguyen, J. Exosomes as therapeutics: The implications of molecular composition and exosomal heterogeneity. J. Control. Release Off. J. Control. Release Soc. 2016, 228, 179-190. [CrossRef]

49. Li, S.P.; Lin, Z.X.; Jiang, X.Y.; Yu, X.Y. Exosomal cargo-loading and synthetic exosome-mimics as potential therapeutic tools. Acta Pharmacol. Sin. 2018, 39, 542-551. [CrossRef]

50. Frasch, S.C.; Bratton, D.L. Emerging roles for lysophosphatidylserine in resolution of inflammation. Prog. Lipid Res. 2012, 51, 199-207. [CrossRef] [PubMed]

51. Makide, K.; Uwamizu, A.; Shinjo, Y.; Ishiguro, J.; Okutani, M.; Inoue, A.; Aoki, J. Novel lysophosphoplipid receptors: Their structure and function. J. Lipid Res. 2014, 55, 1986-1995. [CrossRef]

52. Shanbhag, K.; Mhetre, A.; Khandelwal, N.; Kamat, S.S. The lysophosphatidylserines-an emerging class of signalling lysophospholipids. J. Membr. Biol. 2020, 253, 381-397. [CrossRef] [PubMed]

53. Frasch, S.C.; Fernandez-Boyanapalli, R.F.; Berry, K.A.; Murphy, R.C.; Leslie, C.C.; Nick, J.A.; Henson, P.M.; Bratton, D.L. Neutrophils regulate tissue neutrophilia in inflammation via the oxidant-modified lipid lysophosphatidylserine. J. Biol. Chem. 2013, 288, 4583-4593. [CrossRef] [PubMed]

54. Barnes, M.J.; Cyster, J.G. Lysophosphatidylserine suppression of t-cell activation via gpr174 requires g $\alpha$ s proteins. Immunol. Cell Biol. 2018, 96, 439-445. [CrossRef]

55. Ogasawara, D.; Ichu, T.A.; Vartabedian, V.F.; Benthuysen, J.; Jing, H.; Reed, A.; Ulanovskaya, O.A.; Hulce, J.J.; Roberts, A.; Brown, S.; et al. Selective blockade of the lyso-ps lipase abhd12 stimulates immune responses in vivo. Nat. Chem. Biol. 2018, 14, 1099-1108. [CrossRef] [PubMed]

56. Sun, S.; Liu, C. $7 \alpha$, 25-dihydroxycholesterol-mediated activation of ebi2 in immune regulation and diseases. Front. Pharmacol. 2015, 6, 60. [CrossRef] [PubMed]

57. Liu, S.Y.; Aliyari, R.; Chikere, K.; Li, G.; Marsden, M.D.; Smith, J.K.; Pernet, O.; Guo, H.; Nusbaum, R.; Zack, J.A.; et al. Interferoninducible cholesterol-25-hydroxylase broadly inhibits viral entry by production of 25-hydroxycholesterol. Immunity 2013, 38, 92-105. [CrossRef]

58. Blanc, M.; Hsieh, W.Y.; Robertson, K.A.; Kropp, K.A.; Forster, T.; Shui, G.; Lacaze, P.; Watterson, S.; Griffiths, S.J.; Spann, N.J.; et al. The transcription factor stat-1 couples macrophage synthesis of 25-hydroxycholesterol to the interferon antiviral response. Immunity 2013, 38, 106-118. [CrossRef] [PubMed]

59. Schoggins, J.W. Interferon-stimulated genes: What do they all do? Annu. Rev. Virol. 2019, 6, 567-584. [CrossRef]

60. Wang, S.; Li, W.; Hui, H.; Tiwari, S.K.; Zhang, Q.; Croker, B.A.; Rawlings, S.; Smith, D.; Carlin, A.F.; Rana, T.M. Cholesterol 25-hydroxylase inhibits sars-cov-2 and other coronaviruses by depleting membrane cholesterol. EMBO J. 2020, 39 , e106057. [CrossRef] 
61. Bassaganya-Riera, J.; Song, R.; Roberts, P.C.; Hontecillas, R. Ppar-gamma activation as an anti-inflammatory therapy for respiratory virus infections. Viral Immunol. 2010, 23, 343-352. [CrossRef]

62. Ricote, M.; Li, A.C.; Willson, T.M.; Kelly, C.J.; Glass, C.K. The peroxisome proliferator-activated receptor-gamma is a negative regulator of macrophage activation. Nature 1998, 391, 79-82. [CrossRef] [PubMed]

63. Darwish, I.; Mubareka, S.; Liles, W.C. Immunomodulatory therapy for severe influenza. Expert Rev. Anti-Infect. Ther. 2011, 9 , 807-822. [CrossRef]

64. Hou, Y.; Moreau, F.; Chadee, K. Ppar $\gamma$ is an e3 ligase that induces the degradation of nfkb/p65. Nat. Commun. 2012, 3, 1300. [CrossRef]

65. Ciavarella, C.; Motta, I.; Valente, S.; Pasquinelli, G. Pharmacological (or synthetic) and nutritional agonists of ppar- $\gamma$ as candidates for cytokine storm modulation in covid-19 disease. Molecules 2020, 25, 2076. [CrossRef]

66. Gaboon, N.E.A.; Banaganapalli, B.; Nasser, K.; Razeeth, M.; Alsaedi, M.S.; Rashidi, O.M.; Abdelwehab, L.S.; Alahmadi, T.S.; Safdar, O.Y.; Shaik, J.; et al. Exome sequencing and metabolomic analysis of a chronic kidney disease and hearing loss patient family revealed rmnd1 mutation induced sphingolipid metabolism defects. Saudi J. Biol. Sci. 2020, 27, 324-334. [CrossRef] [PubMed]

67. Hassan, M.A.; Al-Sakkaf, K.; Shait Mohammed, M.R.; Dallol, A.; Al-Maghrabi, J.; Aldahlawi, A.; Ashoor, S.; Maamra, M.; Ragoussis, J.; $\mathrm{Wu}, \mathrm{W}$; et al. Integration of transcriptome and metabolome provides unique insights to pathways associated with obese breast cancer patients. Front. Oncol. 2020, 10, 804. [CrossRef] [PubMed]

68. Tabrez, S.; Shait Mohammed, M.R.; Jabir, N.R.; Khan, M.I. Identification of novel cardiovascular disease associated metabolites using untargeted metabolomics. Biol. Chem. 2021, 402, 749-757. [CrossRef]

69. AlGhamdi, A.A.; Mohammed, M.R.S.; Zamzami, M.A.; Al-Malki, A.L.; Qari, M.H.; Khan, M.I.; Choudhry, H. Untargeted metabolomics identifies key metabolic pathways altered by thymoquinone in leukemic cancer cells. Nutrients 2020, 12, 1792. [CrossRef]

70. Shait Mohammed, M.R.; Alghamdi, R.A.; Alzahrani, A.M.; Zamzami, M.A.; Choudhry, H.; Khan, M.I. Compound c, a broad kinase inhibitor alters metabolic fingerprinting of extra cellular matrix detached cancer cells. Front. Oncol. 2021, 11, 612778. [CrossRef]

71. Alzahrani, A.M.; Shait Mohammed, M.R.; Alghamdi, R.A.; Ahmad, A.; Zamzami, M.A.; Choudhry, H.; Khan, M.I. Urolithin a and $\mathrm{b}$ alter cellular metabolism and induce metabolites associated with apoptosis in leukemic cells. Int. J. Mol. Sci. 2021, $22,5465$. [CrossRef] [PubMed]

72. Chong, J.; Xia, J. Metaboanalystr: An r package for flexible and reproducible analysis of metabolomics data. Bioinformatics 2018, 34, 4313-4314. [CrossRef] [PubMed] 